\title{
Diferentes Barreiras à Análise do Custo Total para os Consumidores
}

\author{
Juliana Ventura Amaral \\ Doutorado em andamento em Controladoria e Contabilidade pela Universidade de São \\ Paulo -USP \\ Av. Professor Luciano Gualberto, 908. Butantã, São Paulo/SP. Brasil. CEP: 05508-010 \\ E-mail: juliana.ventura.amaral@usp.br
}

Márcia Figueredo D' Souza Doutorado em Controladoria e Contabilidade pela Faculdade de Economia e Administração da Universidade de São Paulo - FEA/USP Professora da Universidade do Estado da Bahia - UNEB Rua Silveira Martins, 2555. Cabula. Salvador/BA. CEP: 41150-000 E-mail:marciafdsouza@usp.br

\section{RESUMO}

A análise do Custo Total para os Consumidores (CTC) refere-se à avaliação de todos os custos associados à aquisição e ao uso de bens e serviços. Sua utilização traz variados benefícios, mas precisa superar barreiras para ser de fato implantada. Como essas barreiras ainda não foram exploradas segundo variadas perspectivas, este estudo, colocado na forma de um ensaio teórico, investigou o tema. Baseado em conceitos oriundos da contabilidade mental, da teoria institucional e do marketing, este artigo levantou os fatores que atuavam como barreiras para a adoção do CTC segundo as perspectivas de consumidor, de comprador e de fornecedor. Esta pesquisa identificou que a "dor do pagamento", a institucionalização do preço como melhor parâmetro às decisões e a não inclusão do valor na definição dos preços configuravam as principais barreiras de cada perspectiva. Conhecidas essas barreiras, este ensaio também criticou a nomenclatura CTC.

Palavras-chave: Custo Total para os Consumidores. Teoria Institucional. Contabilidade Mental. Valor Oferecido aos Clientes.

\section{Distinct Barriers to the Adoption of Total Cost of Ownership}

\section{ABSTRACT}

The analysis of Total Cost of Ownership (TCO) refers to the evaluation of all the costs associated with the purchase and use of goods and services. Through its use, many benefits are provided, but it needs overcome barriers to be implemented. As these barriers have not yet been exploited in different perspectives, this study investigated the issue, placed in the form of a theoretical essay. Based on concepts from mental accounting, from institutional theory and marketing, this article raised factors which 
acted as barriers to the adoption of TCO, according to the perspectives of the consumer, the buyer and the supplier. This research identified that the "pain of payment," the institutionalization of price as the best parameter to decisions and the no-inclusion of value for the pricing configured the main barriers to each prospect. Known these barriers, this test also criticized the TCO nomenclature.

Keywords: Total Cost of Ownership. Institutional Theory. Mental Accounting. Value offered to customers.

\section{INTRODUÇÃO}

O livro "Principles of Scientific Purchasing", de Norman F. Harriman, editado em 1928, é considerado uma das obras pioneiras a advertir sobre a necessidade de avaliar todos os custos relacionados à aquisição e ao uso de um produto. Implicitamente, o livro demonstrou a importância de calcular todos os custos associados a uma unidade de produto, ou seja, de calcular o custo total para os consumidores, doravante CTC, conhecido na literatura internacional como total cost of ownership (ELLRAM; SIFERD, 1993).

A expansão do conceito propagado por Harriman para outras áreas de conhecimento (além de compras) não foi imediata. Hoffman (2002), por exemplo, frisa que a implantação da análise do CTC como um guia às decisões das entidades foi bastante tardia: indícios, ainda que limitados, de sua aplicação foram observados apenas em 1986, com a Gartner Inc., empresa de consultoria e de pesquisa de mercado de tecnologia na área de $\mathrm{TI}$.

Nos dias atuais, apesar de ser relevante e de já ter seu conceito difundido no meio acadêmico, a análise do CTC permanece pouco aplicada e com escopo restrito (ELLRAM, 1993b; WOUTERS et al., 2005; MILLIGAN, 2000; HURKENS et al., 2006). Tal limitação não tem justificativas plausíveis, já que a análise do CTC favorece tanto as decisões de compra quanto as decisões de vendas. Por um lado, ela permite que os compradores aprimorem suas escolhas de aquisições e de alianças com os fornecedores e, por outro lado, possibilita que os fornecedores encontrem alternativas 
para produzir bens e serviços que otimizem a relação utilidade-custo do seu cliente (ROCHA, 1999).

A literatura até levanta algumas barreiras que restringem a análise do CTC, mas de forma superficial e com pouco amparo teórico. Os trabalhos de Ellram (1993a; 1994; 1995b) e de Ellram e Siferd (1998), por exemplo, que foram os primeiros a abordar o tema, relacionaram três barreiras para avaliar o CTC: barreiras culturais; barreiras de complexidade; e barreiras de disponibilidade de dados. O problema é que o levantamento dessas três barreiras subsidiou-se exclusivamente em estudos de casos realizados pelos autores, sem fazer um paralelo com o arcabouço teórico e, mais, sem investigar teoricamente qual causa-raiz poderia justificar as três barreiras.

Os trabalhos subsequentes sobre o assunto incorreram no mesmo problema porque não adotaram uma visão crítica e simplesmente assumiram que as barreiras relacionadas por Ellram (1993a; 1994; 1995b) e por Ellram e Siferd (1998) eram aquelas que impediam a adoção do CTC (i.e., WOUTERS; ANDERSON; WYNSTRA, 2005; UYER, 2014; VISANI et al., 2016).

Então, julga-se importante revisar, com um novo olhar, os fatores que impedem o uso da análise do CTC como o verdadeiro guia às decisões de compra e de venda. Ademais, é relevante entender se os fatores encontrados nos clientes finais (doravante designados consumidores) são iguais àqueles encontrados nos compradores profissionais e nos fornecedores. Assim, este estudo busca responder à seguinte questão de pesquisa: "quais são as principais barreiras à análise do CTC nos consumidores, nos compradores e nos fornecedores?".

Logo, o objetivo central desta pesquisa é identificar as principais barreiras à análise do CTC nos consumidores, nos compradores e nos fornecedores. Diante das barreiras identificadas, propõe-se o objetivo adicional de debater qual das três partes tende a analisar o CTC em maior extensão e, com base nesse debate, visa-se também trazer uma crítica teórica à terminologia atualmente adotada.

Para atender a esses objetivos, este estudo imerge em reflexões e em exposições lógicas e reflexivas que caracterizam os ensaios teóricos (SEVERINO, 2007). Do ponto de vista teórico, a primeira justificativa deste ensaio sustenta-se na originalidade de 
expandir a identificação das barreiras à análise do CTC para os fornecedores e para os consumidores, já que, tradicionalmente, ela concentra-se nas barreiras para os compradores. A segunda justificativa teórica pauta-se na adoção de uma abordagem interdisciplinar que, além de recorrer à plataforma teórica contábil e de compras, busca apoio em outras áreas de conhecimento, sobretudo da teoria institucional, da psicologia e do marketing. Do ponto de vista prático, este ensaio justifica-se por sinalizar às entidades a necessidade de encontrar maneiras de superar as dificuldades encontradas no processo de análise do CTC para que este seja, de fato, a base para as decisões de compra ou de venda.

Por fim, cumpre ressaltar a importância de estudo do tema CTC. Para Castro (1977), um tema é importante se está relacionado à questão crucial que polariza ou afeta segmento substancial da sociedade. Considerando que, no geral, o preço de compra de uma unidade de produto somente representa de $25 \%$ a $35 \%$ do seu custo total (SOUTES, 2007), é possível perceber o quão relevante é identificar a parcela de 75 a $65 \%$ referente aos outros custos para que as decisões de compra ou de venda sejam tomadas.

\section{CUSTO TOTAL PARA OS CONSUMIDORES}

Uma das primeiras definições encontradas para o CTC conceitua o termo como "uma abordagem estruturada para determinar os custos totais associados à aquisição e ao posterior uso de um dado bem ou serviço de um dado fornecedor" (CARR; ITTNER, 1992). Outra das mais tradicionais definições trata o CTC como "um termo usado para descrever todos os custos associados à aquisição, ao uso e à manutenção de um bem ou serviço" (ELLRAM, 1993b).

Essas duas definições, por si só, já revelam que a conceituação trazida para o CTC, apesar de transcender a mera consideração do preço, permanece com escopo limitado, pois restringe o termo aos custos incorridos na aquisição e no uso de uma unidade de produto. Ao revisar as definições mais citadas sobre o tema, nota-se que a 
limitação a essas duas etapas continua até a atualidade, conforme demonstra o Quadro 1.

\begin{tabular}{|c|c|c|c|}
\hline ELEMENTOS RECORRENTES & ELEMENTOS NÃC & ECORRENTES & DEFINICÕES CONSULTADAS \\
\hline $\begin{array}{c}\text { Todos os custos ou "o } \\
\text { verdadeiro custo" } \\
(1,2,3,4,5,6,7,9,10,13) \\
\checkmark \text { Produto, bem, } \\
\text { mercadoria, serviço e/ou } \\
\text { item. } \\
(1,3,4,5,6,7,8,9,10,12,13) \\
\checkmark \text { Aquisição } \\
(1,2,3,4,7,8,9,10,11,12) \\
\checkmark \text { Uso } \\
(1,3,4,11,12)\end{array}$ & $\begin{array}{c}\begin{array}{c}\text { Descricão } \\
\checkmark \text { Abordagem } \\
(1,12,13)\end{array} \\
\checkmark \text { Artefato (11) } \\
\checkmark \text { Ferramenta de } \\
\text { compras (6,8) } \\
\checkmark \text { Filosofia } \\
(2,5,6,8) \\
\checkmark \text { Metodologia (7) } \\
\checkmark \text { Termo (3) }\end{array}$ & $\begin{array}{c}\text { Componentes } \\
\checkmark \text { Manutenção } \\
(3,4,10) \\
\checkmark \text { Atualização } \\
(10) \\
\checkmark \text { Descarte } \\
(10,12)\end{array}$ & $\begin{array}{ll}\text { 1) } & \text { Carr e Ittner (1992) } \\
\text { 2) } & \text { Ellram (1993a) } \\
\text { 3) } & \text { Ellram (1993b) } \\
\text { 4) } & \text { Ellram e Siferd (1993) } \\
\text { 5) } & \text { Ellram (1994) } \\
\text { 6) Ellram (1995b) } \\
\text { 7) } \text { Dobler e Burt (1996) } \\
\text { 8) Ellram e Siferd (1998) } \\
\text { 9) Degraeve e Roodhoft } \\
\text { (1999) } \\
\text { 10) Hoffman (2002) } \\
\text { 11) Wouters, Anderson e } \\
\text { Wynstra (2005) } \\
\text { 12) Snelgrove (2012) } \\
\text { 13) Visani et al. (2016) }\end{array}$ \\
\hline
\end{tabular}

Quadro 1 - Elementos das Definições do CTC

Fonte: Elaboração própria.

Além de notar a permanência da restrição do CTC às etapas de aquisição e de uso de uma unidade de produto, a análise dos elementos recorrentes nas definições, isto é, daqueles elementos que aparecem na maior parte dos conceitos apresentados, permite constatar que há consenso no aspecto central do CTC. Afinal, a ampla maioria das definições frisa que o CTC contempla todos os custos (ou "os verdadeiros custos") associados à aquisição e ao uso de uma unidade de produto, seja essa unidade um bem, uma mercadoria ou um serviço. A falta de consenso é observada no detalhamento e no refinamento das definições, ou seja, na descrição e no levantamento de componentes do CTC.

Praticamente não há hegemonia quando se busca descrever o CTC. Os termos filosofia e abordagem até aparecem em um número maior de definições, mas ainda assim não são mencionados em parcela significativa dos demais conceitos. Um aspecto curioso é que o termo abordagem, além de ser apresentado na primeira definição, é 
aquele que parece estar ganhando força na atualidade, já que é usado nas definições mais recentes.

No que se refere aos componentes do CTC, vale ressaltar que a falta de harmonia é um tanto quanto controversa, já que "todos os custos" (ou "os verdadeiros custos") abrangem, obviamente, toda a vida útil de uma unidade de produto, desde o planejamento de sua aquisição até a destinação final. Em outras palavras, pode-se dizer que, ao trazerem os componentes específicos (i.e., aquisição, manutenção, uso e descarte), as definições invariavelmente restringem seu contexto, excluindo componentes que existiriam em alguns segmentos (i.e., atualização necessária de certos softwares). Posto isto, adota-se neste estudo uma definição mais ampla em que o CTC é o valor presente de todos os custos associados a uma unidade de produto desde o planejamento de sua aquisição até a sua destinação final.

Para operacionalizar a identificação do CTC, isto é, para aferir todos os custos associados a uma unidade de produto desde o planejamento de sua aquisição até a sua destinação final, são executadas basicamente duas etapas: (1) levantamento de todas as atividades executadas para viabilizar a aquisição e o uso de uma unidade de produto; e (2) atribuição dos custos a todas essas atividades (DEGRAEVE; ROODHOFT, 1999).

Degraeve e Roodhoft (1999) enfatizam que as atividades levantadas tendem a ser específicas em cada contexto; entretanto, tradicionalmente, elas tendem a abranger minimamente atividades das categorias de aquisição, de utilização e de manutenção da unidade de produto (ELLRAM, 1993b; ELLRAM; SIFERD, 1993). Outras quatro categorias mais pontuais que vêm ganhando destaque são o transporte, a instalação, a propriedade e o descarte (i.e., HOFFMAN, 2002; SNELGROVE, 2012; CANIATO et al., 2014). Como ilustra o Quadro 2, essas sete categorias demonstram etapas comuns que vão desde o planejamento de aquisição até a destinação final dos produtos. 


\begin{tabular}{|c|c|c|c|c|c|c|}
\hline $\begin{array}{l}\text { PLANEJAMENTO } \\
\text { DA AQUISIÇÃOO }\end{array}$ & & & & & & $\begin{array}{l}\text { DESTINAÇÃO } \\
\text { FINAL }\end{array}$ \\
\hline AQUISIÇÃO & TRANSPORTE & INSTALAÇÃo & PROPRIEDADE & UTILIZAÇÃO & MANUTENÇÃO & DESCARTE \\
\hline $\begin{array}{l}\checkmark \text { Preço de } \\
\text { compra da } \\
\text { unidade de } \\
\text { produto }\end{array}$ & $\begin{array}{l}\checkmark \text { Tarifa de frete } \\
\text { (se transporte } \\
\text { da unidade de } \\
\text { produto é } \\
\text { contratado) }\end{array}$ & $\begin{array}{l}\checkmark \text { Tarifa de } \\
\text { instalação da } \\
\text { unidade de } \\
\text { produto (se } \\
\text { instalação é } \\
\text { contratada) }\end{array}$ & $\begin{array}{c}\checkmark \text { Impostos } \\
\text { decorrentes } \\
\text { da } \\
\text { propriedade } \\
\text { da unidade } \\
\text { de produto }\end{array}$ & $\begin{array}{l}\checkmark \text { Tempo e } \\
\text { insumos (i.e., } \\
\text { energia elétrica, } \\
\text { ligações } \\
\text { telefônicas) } \\
\text { consumidos no } \\
\text { treinamento da } \\
\text { utilização da } \\
\text { unidade de } \\
\text { produto }\end{array}$ & $\begin{array}{c}\checkmark \\
\text { Manutenção } \\
\text { preventiva } \\
\text { da unidade } \\
\text { de produto }\end{array}$ & $\begin{array}{l}\checkmark \text { Tarifa de } \\
\text { descarte da } \\
\text { unidade de } \\
\text { produto (se } \\
\text { descarte é } \\
\text { contratado) }\end{array}$ \\
\hline $\begin{array}{c}\checkmark \text { Preço de } \\
\text { produtos } \\
\text { complementares } \\
\text { necessários } \\
\text { para o } \\
\text { funcionamento } \\
\text { da unidade de } \\
\text { produto (i.e., } \\
\text { estabilizador } \\
\text { para } \\
\text { computador) }\end{array}$ & $\begin{array}{l}\checkmark \text { Impostos } \\
\text { sobre tarifa de } \\
\text { frete (se } \\
\text { transporte da } \\
\text { unidade de } \\
\text { produto é } \\
\text { contratado) }\end{array}$ & $\begin{array}{l}\checkmark \text { Impostos } \\
\text { sobre tarifa de } \\
\text { instalação da } \\
\text { unidade de } \\
\text { produto (se } \\
\text { instalação é } \\
\text { contratada) }\end{array}$ & $\begin{array}{l}\checkmark \text { Seguro e } \\
\text { garantia } \\
\text { estendida da } \\
\text { unidade de } \\
\text { produto }\end{array}$ & $\begin{array}{l}\checkmark \text { Combustível } \\
\text { e insumos (i.e., } \\
\text { combustíveis, } \\
\text { energia elétrica) } \\
\text { consumidos na } \\
\text { utilização da } \\
\text { unidade de } \\
\text { produto }\end{array}$ & $\begin{array}{c}\checkmark \\
\text { Manutenção } \\
\text { corretiva da } \\
\text { unidade de } \\
\text { produto }\end{array}$ & $\begin{array}{l}\checkmark \text { Impostos } \\
\text { sobre tarifa de } \\
\text { descarte da } \\
\text { unidade de } \\
\text { produto (se } \\
\text { descarte é } \\
\text { contratado) }\end{array}$ \\
\hline $\begin{array}{l}\checkmark \text { Custos de } \\
\text { financiamento } \\
\text { ou descontos } \\
\text { relacionados ao } \\
\text { pagamento da } \\
\text { unidade de } \\
\text { produto }\end{array}$ & $\begin{array}{c}\checkmark \text { Tempo e } \\
\text { insumos (i.e., } \\
\text { combustível, } \\
\text { estacionamento) } \\
\text { consumidos no } \\
\text { transporte (se } \\
\text { transporte da } \\
\text { unidade de } \\
\text { produto é } \\
\text { próprio) }\end{array}$ & $\begin{array}{c}\checkmark \checkmark \text { Tempo e } \\
\text { insumos (i.e., } \\
\text { combustível, } \\
\text { estacionamento) } \\
\text { consumidos na } \\
\text { instalação da } \\
\text { unidade de } \\
\text { produto (se } \\
\text { instalação é } \\
\text { própria) }\end{array}$ & $\begin{array}{c}\checkmark \text { Tarifas } \\
\text { decorrentes } \\
\text { da } \\
\text { propriedade } \\
\text { da unidade } \\
\text { de produto } \\
\text { (i.e., } \\
\text { condomínios) }\end{array}$ & $\begin{array}{c}\checkmark \text { Preço dos } \\
\text { produtos } \\
\text { complementares } \\
\text { consumidos na } \\
\text { utilização da } \\
\text { unidade de } \\
\text { produto (i.e, } \\
\text { estacionamento } \\
\text { para veículos) }\end{array}$ & & $\begin{array}{c}\checkmark \text { Tempo e } \\
\text { insumos (i.e., } \\
\text { combustível, } \\
\text { estacionamento) } \\
\text { consumidos no } \\
\text { descarte da } \\
\text { unidade de } \\
\text { produto (se } \\
\text { descarte é } \\
\text { próprio) }\end{array}$ \\
\hline
\end{tabular}

Quadro 2 - Exemplos de Custos das Sete Categorias do CTC Fonte: Elaboração própria.

Após serem levantadas as atividades específicas a cada contexto, Degraeve e Roodhoft (1999) sugerem atribuir os custos a todas elas. Ellram (1994) advoga um processo mais simplista, no qual apenas os custos mais relevantes sejam mensurados, já que, segundo a autora, geralmente $20 \%$ dos componentes de custos correspondem a $80 \%$ do CTC. Já é possível encontrar planilhas, programas de softwares e serviços de consultoria no meio profissional e trabalhos acadêmicos que ajudam a calcular esses custos. 
Em suma, pode-se entender que a análise do CTC implica a identificação e a mensuração de todos os custos (ou, de uma forma mais simplista, dos custos mais relevantes), associados a uma unidade de produto desde o planejamento de sua aquisição até a sua destinação final. Ao revelar essa figura mais completa, e não só o preço, a análise do CTC permite que os consumidores, os compradores e os fornecedores aprimorem suas decisões de compra e de venda (SILVA et al., 2012).

Para os consumidores e para os compradores, Ellram (1994; 1995b) assegura que a análise do CTC traz como benefícios, pelo menos, a melhoria nas seguintes deliberações: (1) escolha do produto que será comprado; (2) decisão a respeito do produto no sentido de ele ser mesmo comprado; (3) seleção do fornecedor; (4) decisão sobre o fornecedor no sentido de ele ser mantido, recompensado ou dispensado; e (5) estabelecimento de parcerias com os fornecedores.

Os fornecedores, por sua vez, veem no CTC fundamentos mais consistentes para analisar o valor do produto que oferecem. Vale destacar que essa análise é elementar, pois, como Colauto et al. (2005) ressaltam, o preço colocado pode ser utópico se o vendedor não conseguir identificar o valor que seu produto ou serviço proporciona ao comprador. Analiticamente, de acordo com Piscopo et al. (2008), com a informação do CTC, os fornecedores conseguem melhor:(1) entender o valor que oferecem para os clientes; (2) demonstrar o valor oferecido aos clientes; (3) descobrir oportunidades de ganhos mútuos com alianças; (4) sustentar definições de preços ancoradas no valor; e (4) aprimorar a comunicação e estreitar o relacionamento com os clientes.

Embora a análise do CTC traga esses benefícios às deliberações de aquisições e de vendas, ela ainda é relativamente pouco encontrada da prática (ERIKSON; ARVOLA, 2015). Barreiras culturais, barreiras de complexidade e barreiras de disponibilidade de dados (ELLRAM, 1993a; 1994; 1995b; ELLRAM; SIFERD, 1998) são normalmente apresentadas para explicar essa baixa adesão, sem fazer qualquer segregação entre o uso em consumidores, compradores e fornecedores. Diante dessa fragilidade, a próxima seção busca identificar a causa-raiz que há detrás dessas três barreiras, separando-a por cada tipo de tomador de decisão. 


\subsection{Barreiras à Análise do Custo Total para os Consumidores}

\subsubsection{Consumidores}

Neste ponto do artigo, cumpre destacar a diferença entre compradores e consumidores. Segundo o Código do Consumidor, "consumidor é toda pessoa física ou jurídica que adquire ou utiliza produto ou serviço como destinatário final" (BRASIL, 1990). Dessa forma, embora o consumidor sempre seja comprador, o comprador nem sempre é consumidor, já que pode adquirir um produto para usá-lo nos seus processos produtivos, revendê-lo ao consumidor, presenteá-lo ou para outras finalidades que não a utilização final.

A análise do CTC, sob a perspectiva do consumidor, é pouco explorada na literatura (SILVA et al., 2012), entretanto é uma perspectiva plausível, já que os consumidores, ao adquirirem um bem, considerando o uso que dele pretendem fazer, têm condições de identificar e mensurar todos os custos associados a esse bem.

Entretanto, os consumidores são indivíduos e, de acordo com Cohen (1981), os indivíduos têm comportamentos que nem sempre estão de acordo com os princípios econômicos. Diversas evidências comportamentais mostram que os axiomas econômicos de racionalidade podem não explicar a contento as deliberações dos indivíduos. Uma das correntes dessa literatura, denominada contabilidade mental, discute o conjunto de operações cognitivas que os indivíduos executam para organizar, analisar e acompanhar os eventos financeiros em que se envolvem (THALER, 1985).

A contabilidade mental fundamenta-se nas ideias de Thaler (1980, 1985), corroboradas por experimentos de Kahneman e Tversky (1981), e defende que as decisões dos indivíduos são guiadas pela articulação das diferentes vantagens e desvantagens dos eventos financeiros em "contas mentais" (DUXBURY et al., 2005; GRINBLATT; HAN, 2005). As contas mentais são categorias que incluem as vantagens e desvantagens (informação avaliada positiva e negativamente) dos eventos financeiros (HENDERSON; PETERSON, 1992). A agregação ou a desagregação dos eventos ocorre de diferentes maneiras, de acordo com as circunstâncias encontradas, sendo que as seguintes tendências podem ser observadas: 
- Segregação de ganhos - Por exemplo, é preferível os indivíduos ganharem na loteria um prêmio de $R \$ 50$ e outro de $R \$ 25$ do que ganharem apenas um prêmio de $\mathrm{R} \$ 75$;

- Integração de perdas - Por exemplo, é preferível os indivíduos receberem uma autuação da Receita Federal de $R \$ 150,00$, do que serem autuados pela Receita Federal em R $\$ 100,00$ e pela Receita Municipal em $\mathrm{R} \$ 50,00$;

- Integração de pequenas perdas a grandes ganhos - Como a função de perda se sobrepõe à função de ganho, o cancelamento de uma perda contra um ganho oferece aos indivíduos mais utilidade do que avaliar o ganho e a perda separadamente para depois serem combinados;

- Segregação de grandes perdas e pequenos ganhos - As grandes perdas combinadas a pequenos ganhos não vão modificar a situação das perdas, mas, mantidas separadamente, podem fazer com que os ganhos sejam vistos como um "consolo" (FENNEMA; KOONCE, 2010).

Após estarem agregados ou desagregados, os eventos são codificados como algo bom ou algo ruim (good or bad deal) (FENNEMA; KOONCE, 2010). No que se refere especificamente às aquisições, o consumidor obtém tanto algo bom, relacionado à satisfação trazida, quando algo ruim, associado à "dor do pagamento" (PRELEC; LOEWENSTEIN, 1998).

Há eventos de aquisições simples que são contabilizados mentalmente, cujos custos são incorridos simultaneamente à obtenção dos benefícios. Por exemplo, em um jantar de $R \$ 75,00$, num restaurante que não envolva necessidade de locomoções, o pagamento (de $R \$ 75,00$ ) é a única perda imputada para se ter o ganho associado à satisfação do jantar. No entanto, as aquisições normalmente implicam eventos complexos, cujos benefícios se propagam pelo tempo e demandam vários componentes a serem pagos. Por exemplo, a aquisição de um carro envolve diversos benefícios pela possibilidade do seu uso (passeios, trabalhos, etc.) e incorre em 
diversos custos ao longo da sua vida útil, como pagamentos de empréstimos, custos operacionais com combustíveis, seguros, etc.

Dessa forma, por mais que, de um ponto de vista racional, os consumidores tenham condições de saber qual é o custo total associado às suas aquisições, de um ponto de vista hedônico, querem minimizar os pensamentos na "dor do pagamento". Posto na forma de um paradoxo, pode-se dizer que os consumidores desejam saber os custos da unidade do produto adquirido, mas não querem pensar excessivamente sobre esses custos (PRELEC; LOEWENSTEIN, 1998).

Ora, se os consumidores pensassem excessivamente na "dor do pagamento", eles poderiam optar por não adquirir a unidade de produto que realmente desejam, já que, de acordo com Kivetz (1999), as escolhas de consumo podem ser diferentes quando são feitas sem pensar em razões e consequências. $O$ autor frisa que a mentalidade do consumidor não é igual à mentalidade de um tomador de decisão racional. Enquanto o tomador de decisão tem a tarefa de aceitar ou rejeitar opções, sabendo que suas decisões podem ser questionadas, o consumidor não está preocupado com críticas porque sua tarefa é simplesmente consumir.

Diante dessa exposição, presume-se que os consumidores podem optar propositalmente por não analisar o CTC para assim fazerem a escolha que mais thes agrada, independentemente de ela ser ou não a mais custosa. Em outras palavras, pode-se dizer que os consumidores querem evitar pensar na "dor de pagamento" ao fazerem suas aquisições e, para isso, esquivam-se da análise do CTC. Assim, traz-se que, para os consumidores, a "dor do pagamento" é a principal barreira à análise do CTC.

\subsubsection{Compradores}

A literatura geral sobre CTC, tanto nacional quanto internacional, prioriza a perspectiva do comprador, inclusive no que se refere às barreiras para a sua adoção. As barreiras culturais, de complexidade e de disponibilidade de dados, propostas por Ellram (1993a; 1994; 1995b) e por Ellram e Siferd (1998), nessa perspectiva, são até hoje as mais citadas. 
As barreiras culturais implicam principalmente resistência à mudança de uma orientação exclusiva por preço para uma orientação pelo CTC, já que "o preço é tudo" para alguns profissionais de compras. As barreiras de complexidade também implicam resistência à mudança, especialmente pela falta de conhecimento de que o CTC não é inflexível nem meramente teórico. Por fim, as barreiras de disponibilidade de dados novamente estimulam a resistência à mudança, pois explicitam que não é possível operacionalizar o CTC se informações prontamente acessíveis e modelos de mensuração que capturem dados adicionais ao preço de aquisição não estiverem disponíveis (ELLRAM, 1993a; 1994; 1995b; ELLRAM; SIFERD, 1998).

Dessa maneira, observa-se que, nos compradores, a resistência à mudança explica reiteradamente a baixa adesão à análise do CTC. Considerando que a teoria institucional defende que a incorporação de novas rotinas e regras está sujeita à resistência de desafiar os significados e valores previamente existentes (DIMAGGIO; POWELL, 1983; SCAPENS, 2006), entende-se que as três barreiras relacionadas para os compradores podem ser resumidas em um único fator: a institucionalização do preço como melhor parâmetro às decisões de compra.

A teoria institucional, na vertente da nova sociologia institucional (New Institutional Sociology - NIS), traz o conceito de isomorfismo e explica que existe um processo que força uma unidade na população a se assemelhar a outras unidades que lidam com as mesmas condições ambientais (DIMAGGIO; POWELL, 1983). Van der Steen (2005) defende que o isomorfismo institucional explica que as organizações tendem a adotar procedimentos similares por meio de três diferentes tipos de pressões, dentre as quais as pressões miméticas destacam-se no contexto da não adoção da análise do CTC.

As pressões miméticas decorrem da incerteza, uma vez que ela fomenta a imitação e incentiva as organizações a tomarem outras organizações como modelo (DIMAGGIO; POWELL, 1983). Rezende (2009) entende que as práticas implantadas por força do isomorfismo mimético são percebidas como vantajosas porque poupam esforços. O autor também resume que a semelhança das organizações decorrente das pressões miméticas origina-se da "DÚVIDA". Afinal, na dúvida de qual prática adotar, as 
organizações optam por copiar as outras organizações, sobretudo aquelas de sucesso e com boa reputação (GRANLUND; LUKKA, 1998).

Nesse sentido, entidades que já guiam suas decisões de compras exclusivamente pelo preço e que veem que outras organizações de sucesso também fazem assim tendem a tê-lo institucionalizado como melhor parâmetro e não desejam aprender o que constitui o CTC, tampouco querem buscar informações e elaborar modelos de informação que capturem informações alheias ao preço.

Milligan (2000) traz depoimentos que ilustram a busca contínua dos compradores por argumentos que justifiquem a posição contrária à mudança. Num desses depoimentos, os compradores criticam a análise do CTC pela sua eventual necessidade de lidar com informações subjetivas. Ora, os compradores alegam que, diferentemente do preço, as informações subjetivas são mais difíceis de ser avaliadas e não estão prontamente disponíveis, já que, conforme Morssinkhof et al. (2011) e Anderson e Dekker (2009) relatam, os sistemas de custos tendem a ignorar tais tipos de informações. Esse e os demais depoimentos buscam, de qualquer forma, fragilizar a análise do CTC para contestar a mudança e permitir que o preço permaneça sendo o principal parâmetro de definição das compras.

Com isto posto, entende-se que as pressões miméticas aparecem como respostas padrões para incerteza (DIMAGGIO; POWELL, 1983; SCAPENS, 2006) e fazem com que os compradores de variadas entidades permaneçam usando o preço para as deliberações de aquisições, por mais que, do ponto de vista econômico, ele não seja a melhor opção. Daí infere-se que, para os compradores, a institucionalização do preço como melhor parâmetro às decisões de compra é a principal barreira à análise do CTC.

\subsubsection{Fornecedores}

As principais barreiras à análise do CTC nos compradores e nos consumidores não tendem a ser replicadas nos fornecedores. Primeiramente, os fornecedores não enfrentam a "dor do pagamento" (pelo contrário, têm o "prazer do recebimento") e, consequentemente, não vislumbram nenhum problema em analisar demasiadamente 
os custos incorridos pelos consumidores. Em segundo lugar, é pouco provável que o preço esteja institucionalizado como único guia às decisões de vendas, já que, segundo Silva et al. (2012), os fornecedores conseguem, ainda que superficialmente, obter e organizar informações a respeito dos custos que serão incorridos pelos compradores após a aquisição da unidade de um produto.

Além de não enfrentarem as barreiras que os consumidores e os compradores enfrentam, os fornecedores julgam de antemão que a análise do CTC é importante. Isso ocorre porque, segundo Colauto et al. (2005), a análise do CTC é elementar para que os fornecedores consigam identificar o valor oferecido aos clientes.

Woodruff (1997) explica que o valor oferecido aos clientes é um conceito que envolve o balanceamento entre tudo o que os clientes recebem num produto (i.e., qualidade, benefícios, utilidades) e tudo o que eles sacrificam para ter e manter esse produto (i.e., CTC). Posto em uma estruturação lógica, o valor pode ser visto como resultado da subtração do conjunto de sacrifícios que o cliente tem para obter, utilizar e descartar um produto, incluindo seu preço (que pode ser o CTC) do benefício total para o cliente (que se refere ao valor monetário de um conjunto de benefícios econômicos, funcionais e psicológicos que o cliente obtém de um produto). O valor para o cliente é positivo quando ele proporciona mais benefícios do que sacrifícios e negativo quando proporciona mais sacrifícios do que benefícios (KOTLER; KELLER, 2012).

Kotler e Keller (2012) explicam que, na atualidade, o êxito das vendas está na demonstração aos clientes que os produtos oferecidos, de alguma forma, entregam mais valor que os demais produtos disponíveis no mercado e, para tanto, defendem a colocação de preços condizentes ao valor oferecido. Entretanto, de acordo com Hinterhuber (2008), a definição de preços conforme o valor oferecido aos clientes é, na realidade, ainda muito pouco aplicada. $O$ autor afirma que as entidades permanecem preferindo estabelecer preços com base em informações da concorrência e de custos (ao invés de com base em informações de valor), colocando preços que conduzem à não concretização de vendas.

Como os preços não são definidos com base no valor, os fornecedores não encontram incentivos para voluntariamente analisarem o CTC; afinal, não obterão 
nenhum benefício por fazê-lo. Nesse sentido, a menos que os clientes exijam que haja uma revelação do CTC que os produtos acarretam, os fornecedores optam por não realizar a análise.

De fato, não há motivação para os fornecedores empenharem atividades de análise do CTC se não obtiverem qualquer ganho com isso. Ora, a tarefa não tende a ser simples e tampouco trivial, já que os benefícios e os custos variam entre os clientes, dependendo das suas características. Por exemplo, um cliente com linhas de produtos amplas e fragmentadas e com limitado espaço para armazenamento tende a se beneficiar mais pelas entregas just-in-time do seu fornecedor do que um cliente que possui apenas uma linha de produto e dispõe de amplo espaço para guardar seus estoques (HINTERHUBER, 2004).

Nagle e Hogan (2007) destacam que as diferenças mais expressivas são encontradas entre consumidores finais e compradores organizacionais. De modo geral, os consumidores finais valorizam aspectos subjetivos, enquanto que compradores organizacionais valorizam aspectos objetivos (i.e., aperfeiçoamento da produtividade, durabilidade, economia de combustível, desempenho superior, maior confiabilidade, custos de manutenção reduzidos, custos de implantação menores, serviço mais rápido).

Diante dessas considerações, presume-se que, nos fornecedores, o não proveito da análise do CTC iniba sua utilização. É provável que os fornecedores não instituam a análise do CTC porque não definem seus preços a partir do valor e porque seus clientes sequer exigem essa informação (já que têm suas decisões de compras ancoradas exclusivamente nos preços). Infere-se, portanto, que, para os fornecedores, a não definição de preços, conforme o valor oferecido aos clientes, é a principal barreira à análise do CTC.

\subsection{Extensão de Análise do CTC}

A discussão da diferença entre a principal barreira à análise do CTC para os consumidores, para os compradores e para os fornecedores leva a presumir que também haja distinção na extensão da análise do CTC realizada por essas três partes. 
A barreira para os fornecedores da não definição de preços conforme o valor oferecido aos clientes limita a utilidade da análise, mas não impede que a mesma seja executada. Em outras palavras, pode-se dizer que os fornecedores acabam não adotando a análise do CTC porque não têm incentivos para fazê-lo, mas não veem qualquer problema em realizar a análise caso sejam solicitados. Já nos consumidores e nos compradores, a "dor do pagamento" e a resistência à mudança, além de limitarem coíbem a análise do CTC. Afinal, os consumidores não querem, de qualquer maneira, pensar na dor de pagamento, e os compradores não desejam mudar e são contrários a deixar de tomar suas decisões com base nos preços. Dessa forma, presume-se que os fornecedores podem analisar o CTC em extensão maior que os compradores e os consumidores.

No que se refere à comparação entre a extensão de análise do CTC pelos consumidores e pelos compradores, parte-se da constatação de que a "dor do pagamento" aplica-se a todos os consumidores, enquanto a resistência à mudança de uma orientação exclusiva de preço é encontrada naqueles compradores que já tomam suas decisões com base nos preços. Podem surgir novas entidades (e nelas novos compradores) que decidam iniciar suas atividades sem se atarem ao isomorfismo mimético, ou seja, sem copiarem a prática de tomar as decisões de compras meramente com base nos preços. Nessa situação, as entidades já começariam suas deliberações pautadas na análise do CTC, e assim o preço não existiria como fonte de resistência à sua adoção. Em uma visão ainda mais otimista, essas novas entidades poderiam obter êxito e estimular um ciclo virtuoso que estimularia a cópia de decisões pautadas na análise do CTC, ao invés de pautadas no preço. Destarte, presume-se que os compradores podem analisar o CTC em extensão maior que os consumidores.

\section{CONCLUSÕES}

As discussões promovidas neste ensaio permitiram inferir que há diferentes barreiras para a análise do CTC nos consumidores, nos compradores e nos fornecedores. Para os consumidores, a "dor do pagamento" é a principal barreira à 
análise do CTC. Para os compradores, a principal barreira à análise do CTC é a institucionalização do preço como melhor parâmetro às decisões de compra. Já para os fornecedores, a não definição de preços conforme o valor oferecido aos clientes é a principal barreira à análise do CTC.

Considerando que o impacto exercido por essas barreiras é diferente em cada uma das perspectivas, conjecturou-se que: (1) os fornecedores podem analisar o CTC em extensão maior que os compradores e os consumidores; e (2) os compradores podem analisar o CTC em extensão maior que os consumidores. Assim é possível concluir que o termo CTC carrega em si uma forte contradição: o nome do CTC enfatiza o lado do consumidor, quando o consumidor é, na realidade, a parte que menos tende a analisar o CTC.

Este ensaio, ao revisar o arcabouço teórico do CTC, oferece contribuições ao tema. Primeiramente, ele consolida em um único estudo as barreiras à adoção do CTC, segundo diferentes perspectivas, facilitando o acesso a futuros pesquisadores. Em segundo lugar, ao segregar essas barreiras entre consumidores, compradores e fornecedores, ele organiza a plataforma teórica do tema de uma forma estruturada. Finalmente, ao conjecturar a possível extensão da aplicação da análise, ele contribui ao revelar que a terminologia CTC (custo total para os consumidores) merece ser repensada.

Sugere-se que futuros estudos partam das proposições teóricas e confrontem empiricamente a causa para a não adoção da análise do CTC. Ou seja, propõe-se que pesquisas surjam para confirmar, ou mesmo, para refutar a principal barreira elencada neste ensaio em cada uma das três perspectivas.

\section{REFERÊNCIAS}

ANDERSON, S. W.; DEKKER, H. C. (2009). Strategic cost management in supply chains, part 2: Executional cost management. Accounting Horizons, v. 23, n. 3, p. 289305.

BRASIL. Lei n. 8.078, de 11 de setembro de 1990. Brasília. Disponível em: <Www.planalto.gov.br/ccivil_03/leis>. Acesso em: 1/out/2013. 
CANIATO, F.; RONCHI, S.; LUZZINI, D.; BRIVIO, O. (2014). Total cost of ownership along the supply chain: a model applied to the tinting industry. Production Planning \& Control, March.

CARR, L. P.; ITTNER, C. D. (1992). Measuring the cost of ownership. Cost Management, v. 6, n. 3, p. 42-51.

CASTRO, C. M. (1977). A prática da pesquisa. São Paulo: McGraw-Hill do Brasil.

COHEN, L. J. (1981). Can human irrationality be experimentally demonstrated? Behavioral and Brain Sciences, v. 4, p. 317-370.

COLAUTO, R. D.; MECCA, M. S.; MELO, P. A.; BEUREN, I. M. (2005). Variáveis determinantes da precificação baseada no valor: um estudo empírico em instituições de ensino superior privadas do estado de Santa Catarina. In: Coloquio Internacional sobre Gestión Universitaria en América del Sur, V, Mar del Plata. Anais... Mar del Plata: Universidad Nacional de Mar del Plata.

DEGRAEVE, Z.; ROODHOFT, F. (1999). Effectively Selecting Suppliers Using Total Cost of Ownership. The Journal of Supply Chain Management, p. 5-10, winter.

DIMAGGIO, P. J.; POWELL, W. W. (1983). The iron cage revisited: institutional isomorphism and collective rationality in organizational fields. American Sociological Review, v. 48, n. 2, p. 147-160, April.

DOBLER, D. W.; BURT, D. N. (1996). Purchasing and Supply Chain Management. 6 ed. Nova lorque: McGraw-Hill.

DUXBURY, D.; KEASEY, K.; ZHANG, H.; CHOW, S. L. (2005). Mental accounting and decision making: evidence under reverse conditions where money is spent for time saved. Journal of Economic Psychology, v. 26, p. 567-580.

ELLRAM, L. M. (1993a). A framework for total cost of ownership. The International Journal of Logistics Management, v. 4, n. 2, p. 49-60.

ELLRAM, L.M. (1993b). Total cost of ownership: elements and implementation. Journal of Supply Chain Management, v. 29, n. 4, p. 03-11.

ELLRAM, L. M. (1994). A taxonomy of total cost of ownership models. Journal of Business Logistics, v. 15, n. 1, p. 171-191.

ELLRAM, L. M. (1995a). Activity based costing and total cost of ownership: A critical linkage. Journal of Cost Management, v. 8, p. 22-30. 
ELLRAM, L. M. (1995b). Total cost of ownership: an analysis approach for purchasing. International Journal of Physical Distribution \& Logistics Management, v. 25, n. 8, p. 423.

ELLRAM, L. M. (1993). A framework for total cost of ownership. The International Journal of Logistics Management, v. 4, n. 2, p. 49-60.

ELLRAM, L. M.; SIFERD, S. P. (1993). Purchasing: the cornerstone of the total cost of ownership concept. Journal of Business Logistics, v. 14, n. 1, p. 163-184.

ELLRAM, L. M.; SIFERD, S. P. (1998). Total cost of ownership: a key concept in strategic cost management decisions. Journal of Business Logistics, v. 19, n. 1, p. 5584.

ERIKSON, A.; ARVOLA, V. O. (2015). Total cost of ownership in sales and marketing: Demonstrating value beyond the price at Axis Communications AB. Lund: 2. (Dissertação de Mestrado). Faculdade de Engenharia da Universidade de Lund (Suécia).

FENNEMA, B.; KOONCE, L. (2010). Mental accounting in financial reporting and voluntary disclosure. Working Paper, SSRN. Disponível em: <http://ssrn.com/abstract=1717078>. Acesso em: 15/out/2013.

GRANLUND, M.; LUKKA, K. (1998). It's a small world of management accounting practices. Journal of Management Accounting Research, v. 10, n. 1, p. 153-179.

GRINBLATT, M.; HAN, B. (2005). Prospect theory, mental accounting, and momentum. Journal of Financial Economics, v. 78, p. 311-339.

HENDERSON, P. W.; PETERSON, R. A. (1992). Mental Accounting and Categorization. Organizational Behavior and Human Decision Processes, v. 51, p. 92-117.

HINTERHUBER, A. (2004). Towards value-based pricing - an integrative framework for decision making. Industrial Marketing Management, v. 33, p. 765-778.

HINTERHUBER, A. (2008). Customer value-based pricing strategies: why companies resist. Journal of Business Strategy, v. 29, n.4, p. 41-50.

HOFFMAN, T. (2002). TCO: Flawed but useful. Computerworld, v. 36, n. 49, p. 1.

HURKENS, K.; VAN DER VALK, W.; WYNSTRA, F. (2006). Total Cost of Ownership in the Services Sector: A Case Study. Journal of Supply Chain Management, v. 42, n. 1, p. 27-37. 
KAHNEMAN, D.; TVERSKY, A. Choices, values, and frames. (1981). American Psychologist, v. 39, p. 341-350.

KIVETZ, R. (1999). Advances in research on mental accounting and reason-based choice. Marketing Letters, v. 10, n. 3, p. 249-266, August.

KOTLER, P.; KELLER, K. L. (2012). Marketing Management. 14th ed. Upper Saddle River: Prentice Hall.

LALONDE, B. J.; POHLEN, T. L. (1996). Issues in supply chain costing. International Journal of Logistics Management, v. 7, n. 1, p. 01-12.

LEWIS, B. (1997). Total cost of ownership: The real answer begins by asking the right questions. Infoworld, v. 19, n. 35, p. 84.

MILLIGAN, B. (2000). Quest for total cost of ownership continues. Purchasing, v. 129, n. 6, p. 30-32.

MORSSINKHOF, S.; WOUTERS, M.; WARLOP, L. (2011). Effects of providing total cost of ownership information on attribute weights in purchasing decisions. Journal of Purchasing \& Supply Management, v. 17, p. 132-142.

NAGLE, T. T.; HOGAN, J. E. (2007). Estratégia e Táticas de Preços. (4 ed.). São Paulo: Pearson Prentice Hall.

PISCOPO, G. H.; JOHNSTON, W.; BELLENGER, D. N. (2008). Total cost of ownership and customer value in business markets. In: Woodside, A.; Golfetto, F.; Gibbert, M. (Eds.). Creating and managing superior customer value - Advances in Business Marketing and Purchasing. Bingley: Emerald Group Publishing Limited.

PRELEC, D.; LOEWENSTEIN, G. (1998). The red and the black: mental accounting of savings and debt. Management Science, v. 17, n. 1, p. 04-28.

REZENDE, A. J. (2009). Um estudo sobre o processo de desinstitucionalização das práticas contábeis de correção monetária em empresas brasileiras. São Paulo. (Tese de Doutorado). Faculdade de Economia, Administração e Contabilidade da Universidade de São Paulo.

ROCHA, W. Contribuição ao estudo de um modelo conceitual de sistema de informação de gestão estratégica. São Paulo, 1999. (Tese de Doutorado). Faculdade de Economia, Administração e Contabilidade da Universidade de São Paulo.

SCAPENS, R. W. (2006). Understanding management accounting practices: A personal journey. The British Accounting Review, v. 38, p. 1-30. 
SEVERINO, A. J. Metodologia do trabalho científico. (23. Ed). São Paulo: Cortez, 2007.

SILVA, J. O.; ABADE, T.; FEHR, L. C. F. A.; BORINELLI, M. L.; ROCHA, W. (2012). Análise das diferentes abordagens do conceito de Custo Total para o Consumidor. In: Congresso Brasileiro de Custos, XIX, Bento Gonçalves. Anais... Bento Gonçalves: Associação Brasileira de Custos.

SNELGROVE, T. (2012). Value pricing when you understand your customers: Total cost of ownership - Past, present and future. Journal of Revenue and Pricing Management, v. 11 , n. 1 , p. $76-80$.

SOUTES, D. (2007). Custo total de propriedade (TCO): é importante? Para quem? Ciências Sociais Aplicadas em Revista, v. 7, n. 13, p. 84-105.

THALER, R. (1980). Toward a positive theory of consumer choice. Journal of Economic Behavior and Organization, v. 1, p. 39-60.

THALER, R. (1985). Mental Accounting and Consumer Choice. Marketing Science, v. 4, n. 3, p. 199-214.

UYAR, M. (2014). A Research on Total Cost of Ownership and Firm Profitability. Research Journal of Finance and Accounting, v. 5, n. 1, p. 9-14.

VAN DER STEEN, M. P. (2006). Human Agency in Management Accounting Change: a Cognitive Approach to Institutional Theory. Groningen: (Tese de Doutorado). Rijksuniversiteit Groningen (Holanda).

VISANI, F.; BARBIERI, P.; LASCIO, F. M. L.; RAFFONI, A.; VIGO, D. (2016). Supplier's total cost of ownership evaluation: a data envelopment analysis approach. Omega, v. 6, p. 141-154.

WOODRUFF, R. B. (1997). Customer value: the next source for competitive advantage. Journal of the Academy of Marketing Science, v. 25, n. 2, p. 139-153.

WOUTERS, M.; ANDERSON, J. C.; WYNSTRA, F. (2005). The adoption of total cost of ownership for sourcing decisions - a structural equations analysis. Accounting, Organizations and Society, v. 30, p. 167-191.

Data de Submissão: 19/11/2015

Data de Aceite: 02/08/2016 